\title{
Reducing the Duration and Improving Hospitalisation Time by Using New Surgical Tehniques and Psychotherapy
}

\begin{abstract}
ANDRA GEORGIANA TOMA1, PAUL SALAHORU2*, MARIUS VALERIU HINGANU2*, DELIA HINGANU2, LUCIA CORINA DIMA COZMA ${ }^{3}$, ALEXANDRU PATRASCU5, CRISTINA GRIGORESCU 4

${ }^{1}$ Alexandru Ioan Cuza University, Faculty of Psychology and Education Sciences, 11 Carol I Blvd., 700506, Iasi, Romanian

${ }^{2}$ Grigore T. Popa University of Medicine and Pharmacy, Faculty of Medicine, Anatomy Department, 16 Universitatii Str., 700115 , Iasi, Romania

${ }^{3}$ Grigore T. Popa University of Medicine and Pharmacy, Faculty of Medicine, Internal Medicine Department, 16 Universitatii Str., 700115, lasi, Romania

${ }^{4}$ Grigore T. Popa University of Medicine and Pharmacy, Faculty of Medicine, Thoracic Surgery Department, 16 Universitatii Str., 700115, Iasi, Romania

${ }^{5}$ Grigore T. Popa University of Medicine and Pharmacy, Faculty of Medicine, Orthopaedic Surgery Department, 16 Universitatii Str., 700115, Iasi, Romania

As far as surgical techniques are concerned, video-assisted thoracoscopy comes with lot of improved results compared to classical surgical techniques. This technique seems to reduce the parameters reflecting the period of hospitalization, exposure to analgesics, patient's recovery rate, and the level of pain felt. Studies have been conducted that have demonstrated that, hypnosis can significantly improve the duration of pain exposure as well as the intensity perceived by the patient. In domain literature report cases in which hypnosis has been proven effective is in the preoperative preparation of surgical patients. furthermore, by applying hypnosis, positive results are found during the postoperative care of patients. This study aims at the results of video-assisted surgical techniques, and at the opportunity of integrating complementary therapeutic elements such as hypnosis to improve the parameters interested in perioperative care of the surgical patient.
\end{abstract}

Keywords: Surgical tehniques, psychoterapy, thoracoscopy, hypnosis, pain

One of the main goals targeted by the application of different surgical techniques, as well as the introduction of therapeutic elements specific to postoperative care, is the reduction of the period of hospitalization. Also, the patient's comfort is dependent on the period of hospitalization, which also has a significant impacton the total costs acquired during the therapy [1,2].

Therefore, over time, therapeutic elements used in treating surgical patients were in constant evolution, constantly coming up with new approaches that will increase convenience for patients and improving the outcomes $[3,4]$.

As far as surgical techniques are concerned, videoassisted thoracoscopy comes with lot of improved results compared to classical surgical technique [5]. This technique seems to reduce the parameters reflecting the period of hospitalization, exposure to analgesics, patient's recovery rate, and the level of pain felt $[6,7]$.

Besides video-assisted thoracoscopy, a number of noninvasive interdisciplinary approaches can be used, which, according to the literature, have shown that they can improve the parameters mentioned above $[8,9]$.

Studies have been conducted that have demonstrated that, hypnosiscan significantly improve the duration of pain exposure as well as the intensity perceived by the patient. In domain literature report cases in which hypnosis has been proven effective is in the preoperative preparation of surgical patients. furthermore, by applying hypnosis, positive results are found during the postoperative care of patients [10].

The positive effects of hypnosis used in pain management in surgical patients arise due to the subjective nature of pain. Thus, one of the factors that influence the appearance of pain is represented by its anticipation by the patient. From this point of view, we can say that the extent to which pain is felt by the patient can be influenced by techniques that can manipulate elements specific to the placebo phenomenon [10].

This study aims at the results of video-assisted surgical techniques, and at the opportunity of integrating complementary therapeutic elements such as hypnosis to improve theparameters interested in perioperative care of the surgical patient.

\section{Experimental parts}

Materials and methods

For this study, a total of 643 patients were hospitalised in the Thoracic Surgery Clinic of the Pneumophysiology Hospital in lasi.

All patientshospitalized had diagnoses that led to surgery. Surgery was aimed with a curative, diagnostic or palliative purpose, depending on the indication being assessed.

Regardless of the surgical indication, the present study evaluates the dynamics of the medication administration, respectively the duration of hospitalisation, depending on the type of surgery performed in each patient. Through these two parameters, conclusions can be drawn regarding the level of pain experienced by the patient in the postoperative period and in the recovery rate following surgery.

This study also aims at finding solutions for the improvement of these two parameters by applying adjuvant techniques in perioperative therapy.

\footnotetext{
*email: paul.salahoru@yahoo.com; hanganu.marius@yahoo.com
} 


\section{Results and discussions}

The 643 patients listed in the study were hospitalised, presenting various diagnoses that required three categories of surgery, depending on the necessity and purpose.

Thus, we talk about surgical interventions: palliative, curative or diagnostic. Figure 1 shows the numerical disposition of patients according to the type of surgery.

From figure 1 we observe that most of the surgical interventions (48.52\%) were performed for diagnostic purposes. $36.23 \%$ of surgical interventions were performed for curative purposes, and the lowest number of surgical interventions (15.24\%) was performed inpalliative considerations.

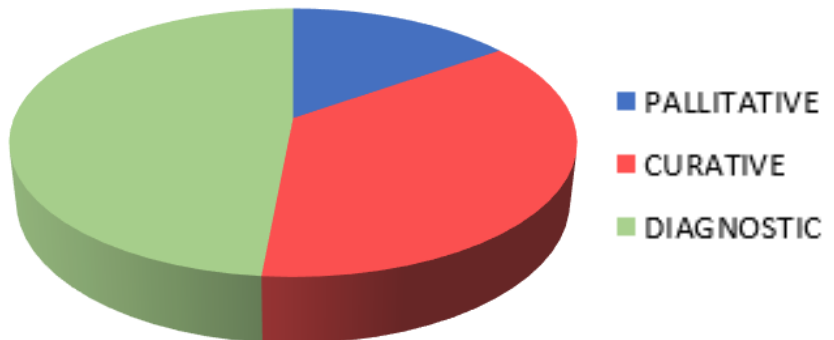

Fig. 1. Numerical diposition of patients included in the study, by the type of surgical intervention

The diagnostic goal of the surgical interventions was imposed by the necessity of obtaining biopsy specimensin the majority of the evaluated patients. Palliative interventions were indicated in patients with neoplastic disease that caused secondary lesions in the pleura, with neoplastic pleural effusion. In these cases, surgery has improved the clinical condition of patients by elimination of the pleural effusion and ameliorating respiratory function. Surgical curative interventions were indicated to patients with non-neoplastic pleural effusions, mostly post-traumatic(hemopneumothorax).

Surgical interventions were performed either by classical surgery (open surgery) or by video-assisted thoracoscopy (VATS). In order to understand the results obtained by video-assisted thoracoscopy, in relation with the two parameters evaluated in this study, the patients were divided into two groups: patients who benefited from classic surgery, respectively patients who benefited from VATS surgery. The numerical values reflecting the distribution of the type of surgical technique in relation with the nature of surgery indication are shown in table 1.

Table 1 highlights that, indifferent of the nature of the surgical indication, the surgical technique used has been distributed approximately uniformly from a numerical point of view. A total of 330 patients (51\%) benefited from classical surgery, and the number of patients using the VATS technique was 313 (49\%). Thus, we can consider that the results obtained are relevant to draw conclusions about the effectiveness of video-assisted thoracoscopy in reducing the duration of hospitalisation, as well as the amount of analgesia administered.

To understand the differences relative to the parameters evaluated in the study, depending on the surgical technique used, we analysed the results obtained and shown in table 2.

The data presented in table 2 highlight major differences in terms of the amount of analgesic administered (expressed during exposure to analgesics), as well as the hospitalisation period in patients who benefited from VATS, compared with patients operated on classical way. Thus, in the case of patients who have had palliative intervention, the duration of analgesic administration is on average $8 \%$ lower and the duration of hospitalization is reduced by $15 \%$. Patients undergoing curative surgery need, on average, a shorter analgesic administration period, reduced by $46 \%$, and the hospitalization period is reduced by half.

By applying VATS, the bestresults are obtained in patients receiving surgery for diagnostic purposes: the average duration of analgesics administration is 54\% lower, and a $68 \%$ shorter hospitalisation period.

Taking into consideration all these data, obtained through descriptive statistics, we can see that it is possible to reduce the amount of analgesics and the duration of hospitalization by using VATS.

Thus, we assert that video-assisted thoracoscopy has notable benefits in reducing pain, as well as increasing postoperative recovery rates.

These two parameters can be improved by using adjunctive elements, represented by hypnosis techniques to reduce pain and improve postoperative recovery, as presented by studies conducted so far.

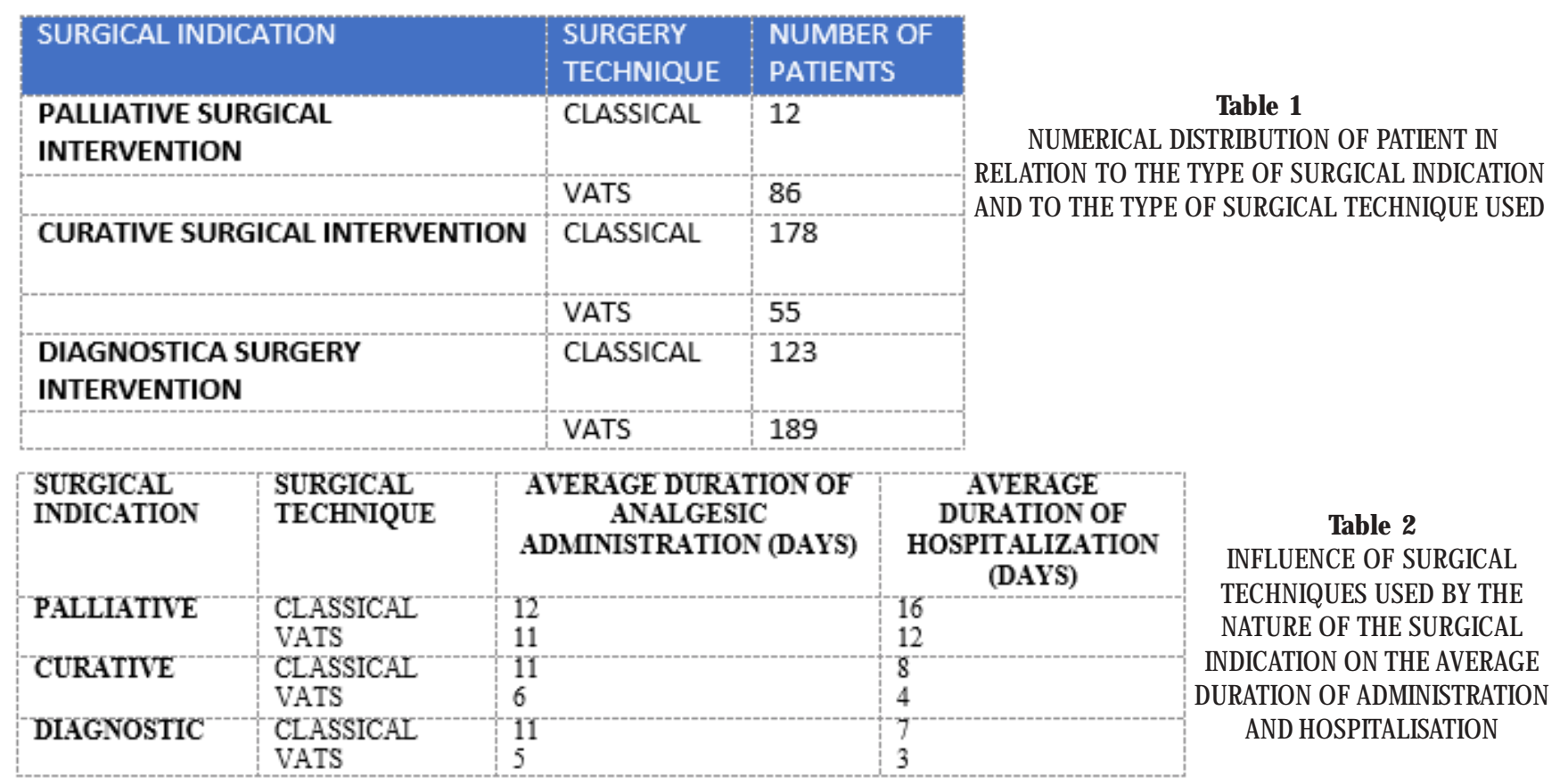


Our study attempts to evaluate the opportunity of introducing hypnosis as complementary therapy in thoracic surgery. From analysis of in-domain literature, the benefits of hypnosis can be represented by: increasing the capacity to overcome anxiety, improving anaesthesia results, increasing analgesia, increasing pain resistance and improving post-operative recovery.

The definition proposed by Montgomery characterizes hypnosis as an agreement between a person designated as a hypnotistand a person designated as a patient or client who participates in a psychotherapeutic technique that produces suggestions for changing sensation, perception, cognition, affection, mood or behaviour.

The primary and crucial element that distinguishes meditation or relaxation hypnosis is the use of the suggestion. Patients asked about this experience describe the following: modified body image, time distortion, dissociation, feelings of relaxation and peace, focusing attention and increasing positive affection, but diminishing memory and self-awareness. From a clinical point of view, there are three phases during the hypnosis session, starting with induction, followed by therapeutic suggestions, and finally the hypnotic state appears [10].

This definition emphasizes the relationship between the hypnotist and the patient, a prerequisite for anyone who practices hypnosis [10].

Similarly, in a randomized study, Defechereux et al. found lower levels of pain, less fatigue, improved recovery and low inflammatory response (IL-6) a day after surgery, with the use of hypnoanalgesia compared to general anaesthesia. Hypnosis techniques improve intraoperative comfort and reduce anxiety, pain and intraoperative requirements for anxiolytic and analgesic drugs while providing optimal surgical conditions and faster recovery rates [11].

In a randomized study, Lang et al. shown that hypnosis is beneficial during invasive medical procedures by lowering symptoms of pain and anxiety, improving hemodynamic stability and shortening surgery times [11].

Studies conducted by Faymonville et al. shows a significant reduction in pain score, anaesthesia use, postoperative nausea, when patients underwent local anaesthesia and hypnosiscompared to general anaesthesia [11].

A case report describes the surgical treatment of a young female patient suffering from pilocytic astrocytoma. The patient refused to have dental treatment under general anaesthesia and demanded hypnosis. As a result of the high acceptance of hypnosis by patients with oral and maxillofacial surgery, Hermes et al. (2002) established a hypnosis procedure incorporated in the activity of the department. Until 2007, 400 traumatological, oral and reconstructive surgeries were performed under local anaesthesia combined with hypnosis [11].

Hypnosis with anaesthetic aim has been used in the following medical procedures: maintaining a leg graft when it was important for the patient to be blocked in a fixed position for a long time; specific cases involving laminectomy, thyroidectomy, vein suturing, recto-vaginal fistula surgery, haemorrhoidectomy, hysterectomy, pneumonectomy, mitral commissurotomy, and cardiac dysplasia;

The hypnotic procedure is meant to minimize bleeding stimulating constructive attitudes, hope and willingness to recover [12].

Among the most useful suggestions that may be given to improve the postoperative recovery of a patient are: a) lack of nausea, b) the ability to cough without pain, c) increased fluid intake and appetite for food, d) a lower amount of narcotics and sedatives need, e) vomit and hiccup reflex control. Ideally, they should be given prior to hypnosis intervention, but they may be given while the patient is still on the table [12].

Marmer (1959) notes the classic indications of hypnosis in anaesthesia and claims to be useful in: a) the ability to overcome anxiety and fear, b) to provide a more comfortable reaction during anaesthesia and postoperative recovery, c) to increase the resilience to pain, and d) the ability to induce anaesthesia and analgesia [12] .

Henry Bennett (1993) has developed and tested new techniques of surgical hypnosis such as: a) reducing the amount of chemical agents required for anaesthesia or their complete replacement; b) reducing the amount of blood lost during surgery; c) restarting blood circulation in the affected area during the healing process, $d$ ) increased healing speed and recovery time after surgery. Bennett believes that hypnosis can also be administered to patients with an average level of hypnotisability [12].

According to in-domain literature, we observe a number of positive effects of hypnosis: a lower amount of medications before surgery increases the ability to recover more quickly after surgery, eliminating the initial fear, pros-traumatization and the chances for the patient to develop anxiety long-term, neurosis or phobiadecreases [12].

Taking into consideration the literature where hypnosis is presented as a potential anaesthetic and analgesic, itis appropriate to carry outfurther studies aimed at assessing the effects of hypnosis in thoracic surgery. It is also essential to monitor the results obtained from the application of video-assisted surgical techniques, along with complementary therapies such as hypnosis techniques for reducing pain and increasing patient comfort in the perioperative period. It is also necessary to consider hypnosis as an alternative to drug anaesthesia, which has the potential to reduce the amount of administered chemical agents, with effects on the cost of therapy as well as on the health of patients [12].

\section{Conclusions}

Video-assisted thoracoscopy brings notable benefits on reducing pain and shortening postoperative recovery time. These two parameters can be improved by using adjunctive elements, represented by hypnosis techniques to reduce pain and improve postoperative recovery.

Both video-assisted surgery techniques, and hypnosis can be applied with the aim of improving recovery of patients. Also, positive results regarding the total hospitalization costs can be found using the two techniques.

A lower amount of drugs before surgery increases the probability that the patients will recover faster after surgery, eliminating initial fear, the pros-traumatization and decreases the chances for the patients to develop longterm anxiety, neurosis or phobia.

It is necessary to consider hypnosis as an alternative to drug anaesthesia, which has the potential to reduce the amount of administered chemical agents, with effects on the cost of therapy, as well as on the health of patients.

The hypnosis procedure is meant to minimize bleeding, stimulating constructive attitudes, hope and willingness to recover.

It is appropriate to conduct new studies to assess the effects of hypnosis in thoracic surgery. 


\section{References}

1.NIMMO SM, FOO ITH, PATERSON HM. J SurgOncol. 2017 Oct;116(5):583-591;

2.SALAHORU, P., GHICIUC, C.M., GRIGORESCU, C., HINGANU, M.V., LUPUSORU, C.E., Rev. Chim. (Bucharest), 69, no.8, 2018, p. 2251 3.GRIGORESCU, C., GAVRIL, L.C., GAVRIL, L., LUNGULEAC, T., CIUNTU, B.M., PATRASCU, A., SALAHORU, P., Rev. Chim. (Bucharest), 69, no. 9, 2018, p. 2591

4.HINGANU D, SCUTARIU MM, HINGANU MV. The existence of labial SMAS - Anatomical, imaging and histological study. ANNALS OF ANATOMY-ANATOMISCHER ANZEIGER, 2018, 218: 271-275. https:// doi.org/10.1016/j.aanat.2018.04.009

5.IONIUC, I. DIACONU, LI. GRIGORESCU, C; ET AL. Procedia Technology, 22 (2016), pp. 413-418;

6.ROMANEC, C., PACURAR, M., DECUSARA, M., SCUTARIU, M.M., HINGANU, D., HINGANU, M.V., CIUPILAN, C., Labio-palatine Cleft, Morphological Substrate. Rev Chim (Bucharest), 69, no. 4, 2018, p. 1002-1005
7.HINGANU D, STAN Cl, TARANU T, HINGANU MV. The anatomical and functional characteristics of parotid fascia. Rom J MorpholEmbryol 2017, 58(4): 1327-1331;

8.CHOU R, LOESER JD, OWENS DK, ROSENQUIST RW, ATLAS SJ, BAISDEN J, CARRAGEE EJ, GRABOIS M, MURPHY DR, RESNICK DK, STANOS SP, SHAFFER WO, WALL EM. Spine (Phila Pa 1976). 2009 May 1;34(10):1066-77;

9.HINGANU, D., HINGANU, M.V., MIHALCEANU, E., CALIN, A.M., PANGA.L, A., COSTACHESCU, G., ROMILA, A.,Rev. Chim. (Bucharest), 69, no. 2, 2018, p. 714;

10.POTIÉ A, ROELANTS F, POSPIECH A, MOMENI M, WATREMEZ C. Anesthesiol Res Pract. 2016;2016:2942416;

11.HERMES, DIRK; STEC, JUTTA; BAHLMANN, LUDGER; KLAUS, STEPHAN. European J ournal of Clinical Hypnosis;2007, Vol. 7 Issue 3, p10;

12.WATKINS J G, ARREED FB. Advanced Hypnotherapy: Hypnodynamic Techniques. Taylor \& Francis, 2008. p. 283-299.

Manuscript received: 21.09.2018 